\title{
Monitoring and treatment iron overload in thalassaemia
}

\section{John Porter}

Red Cell Disorders Unit, University College London Hospitals and UCL, London, UK

\section{Oral presentation}

Oral presentation is available online

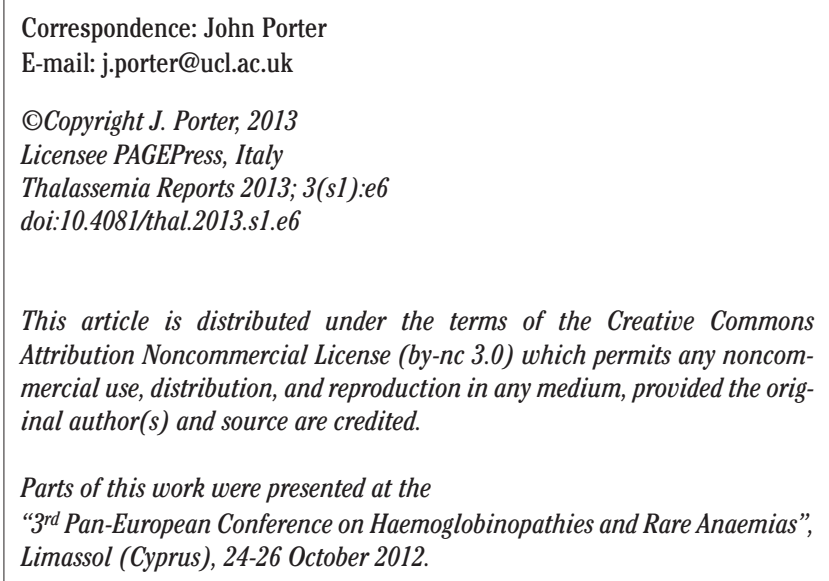

